\title{
Nordic Pioneers: facing the first use of Internet Voting in the Åland Islands (Parliamentary Elections 2019)
}

\author{
Robert Krimmer $^{1}$, David Duenas-Cid ${ }^{1,2}$, Iuliia Krivonosova ${ }^{1}$, Radu Antonio Serrano $^{1}$, \\ Marlon Freire ${ }^{3}$ and Casper Wrede ${ }^{4}$ \\ ${ }^{1}$ Tallinn University of Technology, Akadeemia tee 3, 12618 Tallinn, Estonia \\ ${ }^{2}$ Kozminski University, Jagiellonska 57/59, 03-301 Warsaw, Poland \\ ${ }^{3}$ University of Porto, Praça de Gomes Teixeira, 4099-002 Porto, Portugal \\ ${ }^{4}$ Government of Åland, P. O. B. 1060, AX-22111 Mariehamn, the Åland Islands \\ ${ }^{1}$ [name.surname] dtaltech.ee \\ ${ }^{3}$ marlonfreire@outlook.pt \\ ${ }^{4}$ casper.wrededregeringen.ax
}

\begin{abstract}
The Åland Islands will use Internet Voting for the first time for expatriate voters at the next Parliamentary Elections, to be held in October 2019. This electoral modernization is a response to the need detected to introduce changes in order to better integrate expatriate voters and the younger generations into the electoral system, and represents a first step towards fully introducing i-Voting in future elections. This working paper provides a framework for the Allandic electoral system for further analysis of the costs involved to introduce new voting channels following the CoDE Project methodology.
\end{abstract}

Keywords: The Åland Islands, Internet Voting, Electoral Modernization.

\section{Why this Working Paper? A CoDE Case Study}

This working paper aims to set up the foundations of the case study for the CoDE Project ${ }^{1}$, to be completed in the Åland Islands in October 2019, on the occasion of their initial use of i-Voting.

The present document shortlists a set of elements which we believe to be relevant for understanding the functioning of the Ålandic i-Voting system, including aspects relating to the political and administrative context in which it will be implemented, the narrative and story behind the electoral modernization process and the stakeholders which were involved in it. This information has been collected during May-September 2019, particularly during the visit to Mariehamn in June 2019. This previous work includes a set of meetings and interviews (17) with different members of the Ålandic administration (14), including a previous desk research of literature available on Åland and a detailed analysis of the Electoral Law [4].

The main idea behind CoDE is to provide a useful methodology for calculating the electoral costs using Business Process Reengineering and Time Driven Activity Based

1 Costs of Democratic Elections, 2017-20. Grant ID: PUT1361 
Costing methods $[13,14,17]$. Following this, the next step in the development of our case study will be observation of the electoral process per se, in October 2019, in order to develop the methodology for calculating Electoral Costs [13]. Our calculation methods consist of a set of steps which can be summarized as 1) Modelling the electoral process; 2) Creating the list of activities necessary for conducting the elections and distributing them according to the voting channel to which they apply; 3) Identifying the resource pools and costs assigned; 4) Attributing costs to the activities detected; 5) Calculating the practical capacity of resources; 6) Dividing the total cost per activity by the practical capacities; 7) Calculating the total cost per vote cast for all the activities considered; and 8) Comparing the costs per vote cast for each of the different voting channels.

\section{The Åland Islands: a brief overview}

The Åland islands are a Swedish speaking autonomous region of Finland formed by around sixty inhabitable islands and around six thousand small rocky islands not suitable for human habitation or settlement. The archipelago is situated in the opening to the Gulf of Bothnia, bordering south-western Finland and central-eastern Sweden and is inhabited by 29,789 citizens, 11,743 of them living in the capital, Mariehamn. The economy is based on agriculture, forestry, fishing and the tourist industries [1]. The autonomy of the Åland Islands was affirmed in 1921 by the League of Nations, through which Finland would protect and guarantee the continuation of the culture, language and traditions in the archipelago, and the Ålandic Government would have a say in the obtention of franchise and lands of the isles, by foreigners [3]. Similarly, the autonomy of Åland was reaffirmed by the treaty to admit Finland into the European Union. Amongst other elements of self-government, the Åland islands have their own Parliament (Lagting) and Government (Landskapsregering), elected in their own elections.

\subsection{The Ålandic Electoral System}

The uniqueness of Åland's status translates into the implementation of elections, relating to both the archipelago and Finland. Alland uses the electoral system of proportional representation in which voters cast votes for a particular candidate, not for a party. Votes are transferred into seats using the D'Hondt method. The islands will hold ordinary elections for both the Parliament and Municipal Councils in 2019. To cast a vote in the former, an individual must hold the Åland Right of Domicile, whilst in the latter, if the resident does not hold such an entitlement, he must at least have been an inhabitant of any of the Ålandic municipality for one year prior to election day c.

The legislation regulating these elections is the Election Act for Åland, adopted by the Parliament in January of 2019. Containing 122 articles (or Sections), it details everything ranging from the election authorities and candidates, to voting channels and processes. According to the Act, votes may be cast in advance (at polling stations, at institutions, by post or, for the first time in 2019, via the Internet) or on Election Day (at polling stations only). Advance voting by post can be carried out from the $27^{\text {th }}$ day 
before the Election Day (E.D.), until the $2^{\text {nd }}$ day before the E.D. The rest of the advance voting is held between the $15^{\text {th }}$ day before E.D. until the $5^{\text {th }}$ day prior the E.D. Within these dates, advance voting at institutions will be held for 2 days at most, and advance Internet voting will be held for a minimum of 120 hours (please refer to Fig. 1 for illustrative purposes). If multiple ballots are cast during the advance period, precedence is given to paper votes cast at the polling station, over the postal ballot, which in turn trumps the Internet vote. Finally, once the voter has decided to participate in any type of advance voting, they will not be able to cast their vote on E.D. [4].

\section{September 2019 October 2019}

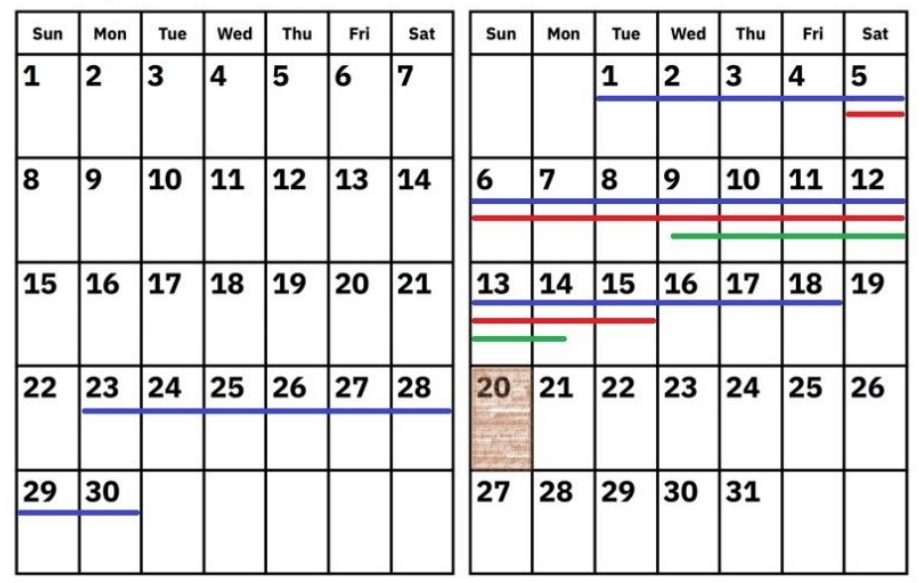

Fig. 1. October $20^{\text {th }}$ is Election Day. The 2019 advance voting periods are shown as: blue - postal voting; red - polling station voting; and green - Internet voting.

In the past, the overall election turnout in the Åland Islands has been quite positive even before the introduction of Internet voting, with a general trend for women to vote more than men $^{2}$, contrary to the many European countries. However, the Ålandic officials still consider the turnout quite low, from the Nordic perspective. Since the 1971 Parliamentary elections, the turnout has been kept above $60 \%$ and even reached $70 \%$ for the first time in the 2015 Parliamentary elections [19]. However, the distribution of turnout ranged from $54 \%$ to $73 \%$ in municipalities in the most recent elections (2019 Parliamentary elections) (see Figure 2) and from $64 \%$ to $77 \%$ in the most recent local elections (2015 Municipal elections) (see Figure 3).

2 According to the data provided by Statistics and Research Åland, see: www.asub.ax/sv/statistik/valet-europaparlamentet-2019 


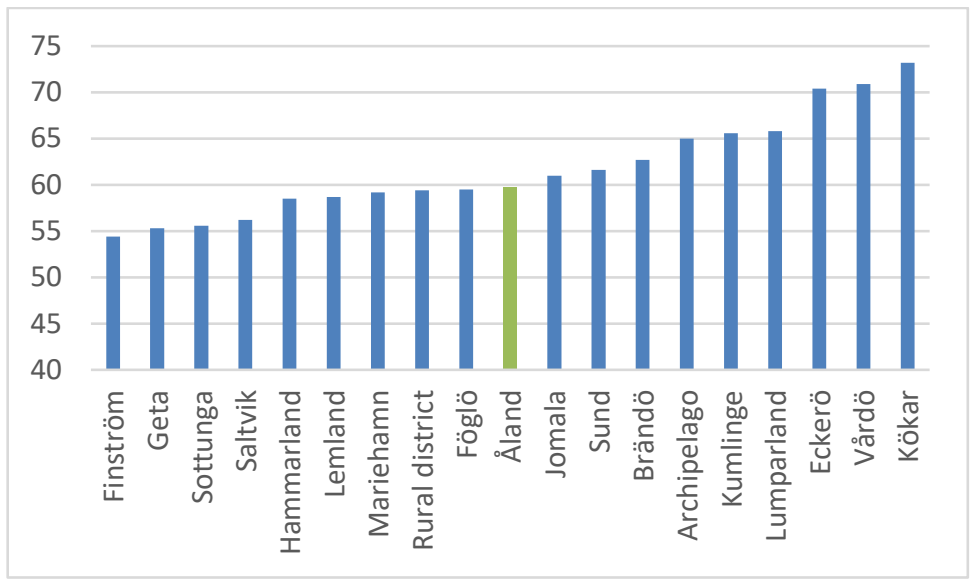

Fig. 2. Turnout Distribution for elections to the Parliament of Finland 2019.

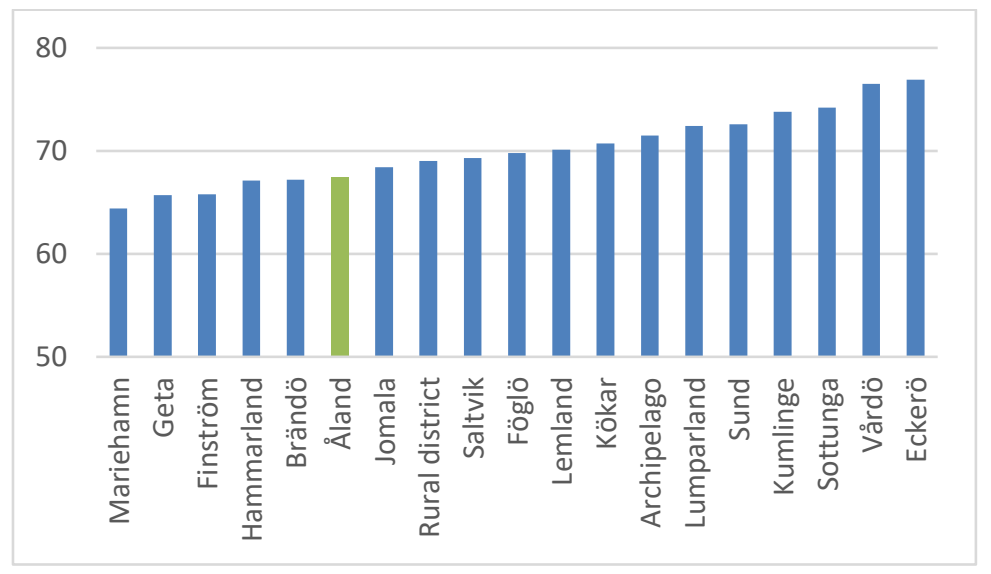

Fig. 3. Turnout Distribution for Municipal local council elections 2015.

\section{Why the Åland Islands decided to do it? Drivers for implementing Internet voting}

\subsection{The long road to Internet voting: from 1999 up until today}

The initial idea, at the end of the 1990's, to implement a form of electronic voting in the archipelago, was spearheaded by a minister (Danne Sundman) and was mostly political in nature. This resulted in the creation of an investigative committee which researched different international tools and methods of e-voting. Their 2001 result highlighted, among other things, both the advantages and disadvantages of i-Voting, and recommended not introducing it until the voter integrity and identification issues had been resolved [21]. 
Several years later, Finland attempted to trial some electronic voting machines in three municipalities for the 2008 local elections. Ålandic officials were invited to observe the proceedings. The total costs of the project was reported to be 1,630,550 euros [9], but the attempt was deemed a failure and the whole election was scrapped due to inadequate testing of voting software [21].

\section{“...this closed the discussion about electronic voting in Finland for 10 years" (Interview 3, Day 1).}

Fast forward to 2014, when an internal committee was set up by the Government of Åland to reform the electoral system. Amongst the proposals presented in their 2015 report, they recommended the initial introduction of i-Voting as an additional advance voting channel, only applicable to people living outside of Åland, who would only be permitted to vote for the next Parliament. By 2023, and based on the results of the 2019 experience, i-Voting would be available to all voters [21]. The Government of Åland adopted the electoral reform proposals in 2016 and efforts to implement i-Voting commenced. The preparations for implementing Internet voting in Åland included research activities by multiple working groups, involvement of external experts (from Estonia, Denmark, Norway, Spain and Sweden), study visits to countries successfully implementing i-Voting, participation with papers at scientific conferences for the Internet voting community.

\subsection{Convenience, expatriate voters and turnout: usual suspects for the adoption of Internet Voting}

Given the geographic situation of the Åland Islands, making voting more convenient for remote voters has been a long term goal of electoral authorities [20], as well as a traditional element considered as a driver for Internet voting. The logic is based on two assumptions that 1 ) there is a general demand for convenience voting channels among the populous; and 2) there is trust established towards remote voting channels, arising in an uncontrolled environment.

The Åland Islands have a legacy of convenience and remote voting channels being available to the population. Considering convenience voting, Åland offers "early voting at a general early voting location during the early voting period" which is not linked to the place of residence, hence, a voter could vote at any early voting polling station across Åland during the 11 day period; early voting at care institutions ${ }^{3}$ and election day voting. Advance voting channels are quite popular amongst the populace and currently are used by around 1/3 of all voters who cast a vote (35\% in 2019 and $2014 \mathrm{EU}$ Parliament Elections $)^{4}$. Since 1987, Åland has been using postal voting, convenience voting and remote voting channels. Postal voting might be used by those who "are out

\footnotetext{
3 As described in the leaflet produced by the government of Åland to explain the functioning of Elections to the citizens: "Election on Åland, 18 October 2015".

4 Aland Statistic Agency, URL: https://www.asub.ax/sv/statistik/valet-europaparlamentet-2019
} 
of the country or are ill/handicapped and unable to vote in any other way"5. Though, it has not become a popular choice among voters due to the cumbersome procedure. In the 2015 Legislative Assembly elections, the most recent elections where postal voting was used, about 150 people voted by post [7], which constitutes only $0.7 \%$ of overall voters eligible. Also, about $10 \%$ of postal ballots arrived too late to be counted in the elections. Overall, reportedly, the postal service is getting slower in the Åland Islands over the years (Interview 3, Day 1, June 2019) which could result in even more votes not been delivered on time in future elections. In 2015, voters who applied for postal voting also received a questionnaire on whether they would be interested in Internet voting, and only 9 out of 115 respondents replied "no" [7].

However, besides postal voting, no other voting channels are available to voters residing outside Åland: as Åland does not have embassies or representative agencies or consulates outside Åland, unlike in other countries, voters do not have the option to vote in foreign missions. Hence, the enfranchisement of expatriates constitutes another driver for introducing i-Voting. Therefore, the target group for initial use of Internet voting is expats. Expatriate voters were also selected as a target group due to the limited size of the group, thus making the first trial of Internet voting more feasible. Another reason for focusing on expatriates is the nature of the electoral cycles and electoral administration in the Åland: two elections, parliamentary and local, are occurring simultaneously. Internet voting is now approved only for parliamentary elections. Hence, to avoid the situation of the same voter being eligible to vote via the Internet in the parliamentary elections, but not eligible in local elections, the target group for the first use of Internet voting in the Åland should be those voters who can vote in parliamentary elections, but not in local ones. The only group satisfying this criterion is expatriate voters.

Similarly, the expectation to positively influence turnout is a third element which strengthens the reflection on electoral modernization. One of the goals of electoral modernization is to be able to have a positive impact on turnout, meaning either to increase it, or to mitigate its decline. Similarly, the expert team formed in the Åland Islands in 2001 to assess Internet voting did not regard Internet voting as being able to increase turnout, but only being a "prerequisite for being able to preserve voter turnout at the current level" [6]. Over time, the expectations have changed somewhat. Through the interviews conducted in 2019, we have learned that officials understand that Internet voting will not really increase voter turnout dramatically. However, they expect at least a slight increase in turnout, although the overall turnout in the Åland is already quite high when compared to other political environments. The concerns, then, are not focused on the general turnout, but on particular groups that are generally more disconnected from political life due to their age, physical or geographical situation.

"if it goes well, technically, and the security issues, and we have a satisfactory, higher turnout, than would be with the old system, then that's enough to continue" (Interview 5, Day 2, June 2019).

5 Leaflet: Election on Åland, 18 October 2015 
Overall, 1,492 expatriates residing in 21 countries are eligible to vote in these elections via the Internet, and all of them have been sent voting cards with information on how they may vote online. Expatriates constitute $6 \%$ of all eligible voters. Most of them (69\%) reside in Sweden and Finland (26\%).

\subsection{Digital pioneers: building the Ålandic Islands’ own narrative in the Nordics}

From the very beginning of the discussion on Internet voting in the early 2000's, it was considered as a measure to "strengthen Åland's IT image" [9]. A few years later, the Ålandic Government created the $\AA \mathrm{DA} \mathrm{A}^{6}$, a company with only public owners, both the Government and (most of) the Åland municipalities, which is providing IT-services for the public sector, to both the government and the municipalities. The aim of $\AA \mathrm{DA}$ is to contribute to digitization of the islands in various different ways and, in the case we are analyzing, it was a key player in implementing the new electoral channel, being in charge of the procurement process which led to the i-Voting solution and owning the contract with the vendor which won the procurement process.

Both the development of i-Voting and digitization of the islands are part of creating a digital narrative of Åland's identity and creating a positive image to promote the Islands as a place where innovation occurs and to highlight the positive impacts of their self-government:

"We are not afraid to try new things" (Interview 3, Day 2, June 2019)

"It \{implementing Internet voting\} could be a good way to show that being small does not mean you need to lag behind" (Interview 5, Day

2, June 2019)

"Aland is a place where you can move faster and introduce new things because of self-governance" (Interview 5, Day 2, June 2019)

It is about "being in the forefront" (Interview 2, Day 2, June 2019) and providing "an important showcase for Internet voting in the Nordic countries, because as you know, Nordic countries have been a bit hesitant here" (Interview 2, Day 2, June 2019).

\subsection{Saving money and time? Secondary topics with uneven expectations of impacts for a first-time experience.}

Implementing innovations in a public administration can be a long and tedious process involving several actors and interests. The process to introduce internet voting was no exception, taking 20 years to consolidate the initial idea. Similarly, the benefits of implementing i-Voting might take some time to become apparent, once the system has

6 Åland Digital Agenda, see: www.ada.ax/ 
been fully implemented and has achieved popularity with the electorate. One of the elements usually included in the list of reasons to consider changing the electoral system, is the expectation that it will also have an impact on the costs of running elections and the time invested by the public administration (in the end, human resources) in managing elections.

The reduction of costs was already mentioned in a 2001 report [6] as a potential advantage to be achieved by introducing Internet voting, but only in the long run. In the 2015 report [7] it was also mentioned that implementing Internet voting should follow two basic conditions: it should be secure and financially justifiable (p. 26). The discourse on costs follows two different approaches. Firstly, the debate on cost-efficiency of the system cannot be tackled in this first attempt, since the population eligible to vote will be significantly reduced and the cost per vote is expected to be very high. This analysis will become more realistic once the i-Voting system is deployed for the entire population (2023). In the meantime, there is the assumption that the system will not be cost-efficient "so this was not the argument \{for implementing Internet voting\}" (Interview 2, Day 2, June 2019). Secondly, in the assessment of costs incurred by procurement of the initial stages of the i-Voting system, officials claim these are "surprisingly cheap", as they managed to obtain a bid at a lower price than expected (Interview 5, Day 2, June 2019).

This argument of swift response times was not on the agenda in the report in the early 2000 's, because the "relatively limited number of votes means that reporting the result is already sufficiently swift" [6]. This argument is repeated in interviews conducted, not neglecting the swiftness of the system, but the size of the electorate is not big, so the impact of $\mathrm{i}$-Voting will be minor in this respect.

"Well, we think that counting electronic takes 5 seconds, perhaps?” (Interview 5, 10 June 2019)

"We are talking about a few hundred votes" (Interview 5, 10 June 2019)

Even if time and cost-efficiency do not seem to be amongst the primary reasons for implementing i-Voting in the Åland Islands, a better assessment of their impact will be possible in future elections, once the size of the electorate grows by extending it to other elections and population groups. The main reasons for introducing Internet voting in the Åland Islands, therefore, can be summarized as those expressed above in the previous points.

\section{Short description of Internet voting system}

The current system is integrated into the Finnish e-Government system when it comes to voter identification.

From the voter's perspective, the system includes the following steps: 
1. Open the Åland e-Government page and read the procedures for i-Voting;

2. Access the I-Voting system;

3. Authenticate in the system (using e-ID card or Mobile ID or Bank ID code);

4. Insert the number or name of the candidate;

5. Confirm and submit the vote;

6. Verify the vote in the electronic ballot box (using the verifiability application - not mandatory);

The authentication system represents a clear step forward in the relationship between the Ålandic administration and voters, since the government does not need to send out letters containing credentials to voters living abroad for voting via the Internet. The iVoting system can be used with three different digital authentication methods to complete this step: e-ID cards, Mobile ID and Bank ID codes. The first two systems are provided by the Finnish e-Government system, whilst the third one is provided by banks and its use is quite widespread throughout the whole of Finland, including the Åland Islands. All the personal identification methods listed are connected to the Finnish Population Register database which implies a raised level of security, reliability and integrity for the voters roll before and during the i-Voting process.

The votes are contained in an electronic ballot box which must be empty and free of vote-records prior to the elections, and which is then sealed using an encryption method. After 8 p.m. on Election Day, the electronic ballot box is decrypted and opened using special digital opening-keys distributed to 5 members of the Central Committee. It will not be possible to open the ballot box unless at least three of these people are present at the same time. Once the system has been decrypted, votes cast can be counted and included in the general results of the election.

\section{$5 \quad$ Assessing New Voting Technologies}

In this section, we apply the methodology developed by OSCE/ODiHR for the Observation of New Voting Technologies [2] to the case of the Åland islands.

\subsection{Procurement and Acquisition of NVT}

In Åland, it is not the government itself, but a particular agency, ÅDA, which is acting as the procurement agent being in charge of the procurement process with the Government as the "real" customer. Scytl won the tender for the 2019 elections. However, for future elections, a new procurement process will be prepared and carried out with renewed competitive tendering. 


\subsection{Role of the Election Administration in the Use of NVT}

\subsubsection{Voting Process Re-Structuring}

Legislatively speaking, the Election Act for Åland was amended with an entire chapter relating to the new i-Voting channel being added. Additionally, other articles were modified to establish the precedence of paper ballots over digital ones, and to adjust those processes and characteristics (dates, transporting votes, updating voter roll lists, etc.) which apply to the implementation of i-Voting. Nevertheless, these updates are not very specific and do not detail the back-end of operations required to implement iVoting.

Regarding the institutions, the new voting channel utilizes the same electoral management bodies as previously existed: the Central Committee for Parliamentary Elections and the Central Municipal Election Board. Laws and the legal process include other entities:

- the Government of Åland, which effectively green lights the implementation of $\mathrm{i}$-Voting and arranges checks of the i-Voting system and the votes (during and after the voting periods);

- Independent bodies which conduct these checks (during and after the voting periods).

Nevertheless, as previously stated, the implementation of the back-end is much more complicated and other stakeholders must be taken into consideration. Since the i-Voting solution is being contracted out, the private company $\operatorname{Scytl}^{7}$ oversees running the iVoting software. The company in turn was employed by ÅDA, originally awarded the bid for the i-Voting solution. A Commission was formed in order to manage the complex discussions which entail the preparation and implementation of such procedures, containing members of the Government Office and said intermediary, and an additional Commission was put in place to handle the keys to the system.

\subsubsection{Multiple Voting Channels: Integration of Electronic and Paper- Based Voting Processes}

On Friday, before the Election Day, the list of those who voted over the Internet, "drawn up by voting district, in alphabetical order by last name"8 is sent to central municipal election board by the central committee for parliamentary elections. Then, the central municipal election board checks if there are voters who voted both in advance on paper and over the Internet, and notify the central committee for parliamentary elections on such instances "no later than 12.00 on election day"

\footnotetext{
${ }^{7}$ Scytl, see: www.scytl.com/en/

${ }^{8}$ Resolution LTB 2/2019 of the Parliament of Åland on the adoption of an Election Act for Åland. Section 84

${ }^{9}$ Resolution LTB 2/2019 of the Parliament of Åland on the adoption of an Election Act for Åland. Section 85 .
} 


\subsubsection{Oversight}

A few state agencies conduct the oversight of Internet voting in Åland: Steering Committee for implementing I-Voting; Åland Data Inspection Authority; company auditing the security of the process. By law, "an election observer appointed by the Government of Åland, a competent Nordic authority or a competent international body is entitled to be present while the election authorities referred to in this Act are performing their duties"10. Besides, each election authority is eligible to entitle other people to participate in the meetings.

On the 20th September, 2019, the Åland Data Inspection Authority published a report on the i-Voting system criticizing inter alia the lack of clarity of contracts between the Government, ÅDA and Scytl, as well as, the issue regarding the personal data of ivoters.

\subsubsection{Voter Education}

All voters eligible to cast a vote over the Internet (this election, only expatriates) receive voting cards with the detailed information on how they could vote online, if they wish.

\subsection{Security and Secrecy of the Vote and Integrity of the Results}

The list of Internet voters is not public "until voting is complete on election day"11. Alike with paper ballots, "the electronic ballot box containing votes cast via the internet shall also be sealed" 12 . Hence, unlike in other countries with Internet voting, in Åland, the electronic votes do not get destroyed since elections are over, but "shall be stored until the following election is held and has become legally valid"13.

\subsection{Usability, Ballot Design, Voter Accessibility and Reliability}

Even though, Åland does not own the system, as Scytl provides them with an Election as a Service solution (EaaS) which means that Åland is using the proprietary software, they will develop an interface to fit the context of the Ålandic elections. The digital ballot will be similar to the paper ballot, which means that a voter would not be able to select a candidate by clicking on it in the list of candidates displayed. A voter will need to insert the number of a candidate, exactly like it is done when a voter cast a vote on paper.

${ }^{10}$ Resolution LTB 2/2019 of the Parliament of Åland on the adoption of an Election Act for Åland. Section 14.

${ }^{11}$ Resolution LTB 2/2019 of the Parliament of Åland on the adoption of an Election Act for Åland. Section 84.

${ }^{12}$ Resolution LTB 2/2019 of the Parliament of Alland on the adoption of an Election Act for Åland. Section 106.

${ }^{13}$ Resolution LTB 2/2019 of the Parliament of Åland on the adoption of an Election Act for Åland. Section 106. 


\subsection{Public Testing}

A pilot test was organized in August 2019 to assess the technical reliability of the iVoting system as well as to ensure the integrity of the list of eligible candidates and voters, to secure methods of identification and authentication for the voters, the electronic ballot box (secrecy of votes, opening and sealing processes), the votes verifiability app, and the overall IT infrastructure. The pilot test revealed some problems.

A new pilot test and a pen-test are to be implemented in the end of September, 2019, with a report to appear in the next week after it. The pen-test is conducted by the Finnish company Nixu. The local IT-company called Deductive Labs has been used for security checking. The i-Voting system was deployed by the government of Åland in cooperation with other entities and a group of 30 volunteers in order to simulate the cycle and procedures of the $\mathrm{i}$-Voting process.

\subsection{Verification Methods}

A vote verification method is available in order to provide transparency and reliability during the i-Voting process, allowing checks on whether the vote has been sent correctly to the electronic ballot box. To do so, the voter must download an application available on the Åland e-Government website and then verify the vote using a QR code which has been sent via the i-Voting system as a receipt/proof of casting a vote. This process is quite similar to the ones followed elsewhere in Estonia [15, 18], Switzerland $[10,16]$ or Norway $[8,11]$.

Besides, the law prescribes the Government of Aland to "arrange for verification of the votes in the electronic ballot box in order to ensure that they have been registered as intended, that they have been stored as they were registered and that they have been counted as they were stored. The verification shall be carried out by an independent body"14.

\section{Final remarks and expectations for the CoDE Case Study}

This working paper identified a set of elements which help us comprehend the 'how and why' of introducing internet voting. The administrative and political uniqueness of the Åland Islands gave their government room to organize a separate electoral system than the Finnish one. However, the Ålandic system still has interesting connections with the (Finnish) state electoral system: for example, how the Ålandic i-Voting system uses the Finnish authentication systems and the population register. Other remarkable facts, we understand, are the motivations for implementing i-Voting and the will to keep expatriate voters involved in Ålandic politics and to incentivize the younger population groups to turn out and vote, but also the combination of this with creating an Ålandic political narrative.

${ }^{14}$ Resolution LTB 2/2019 of the Parliament of Åland on the adoption of an Election Act for Åland. Section 86. 
Regarding our expectations for the CoDE project case study, it is worth remembering that that our aim is to provide a useful methodology for calculating the election costs $[12,13,14,17]$. The core of the project is rooted in the idea that the decision to introduce a new voting channel adds new layers of complexity and financial pressure to electoral management bodies. These decisions are taken, on occasion, without having realistic information on the impacts a new voting channel may have, but based on the expectation of making voting more convenient, increasing voter turnout or of helping to save money and time. The value of the Ålandic case lies on its singularity and pioneering nature. It represents an excellent opportunity to use CoDE methodology in a scenario where a new voting channel will be introduced for the first time, and of being able to track, using real data, the behavior and evolution of cost-efficiency comparisons between established and new voting channels.

Similarly, we cannot avoid mentioning that, given the conditions, the fact this will be the first use of i-Voting in the Ålandic context, we expect (as do the authorities in Åland too) a disproportion will arise between cost-efficiency of traditional paper-based voting and the newly introduced i-Voting system for two main reasons. Firstly, the Internet voting system will be restricted to a reduced number of voters (expatriate voters) and, secondly, the initial use of a voting channel is normally accompanied by a lack of awareness of its existence from some of the potential users, causing a reduced percentage for its use.

\section{$7 \quad$ Acknowledgements}

We would like to extend our thanks for their time and collaboration for the interviews to Ronny Lundström, Ida Ericson, Michaela Slotte, Katarina Donning, Camilla Sundkvist and Joakim Söderberg. Also, to the ministers Nina Fellman and Wille Valve and the whole Government of Åland for letting us be present in the sitting where the Law for I-Voting was approved (Katrin Sjögren, Camilla Gunell, Mats Perämaa, Tony Asumaa and Mika Nordberg).

This work was funded by the Estonian Research Council grant PUT1361.

\section{$8 \quad$ References}

1. (ÅSB) Statistics and Research Åland: Åland in Figures., Mariehamn (2019).

2. (ODIHR), O.O. for D.I. and H.R.: Handbook For the Observation of New Voting Technologies. (2013).

3. Åland Culture Foundation: International Treaties and Documents Concerning Åland 1856 - 2009, http://www.kulturstiftelsen.ax/traktater/eng_fr/ram_rightenfr.htm.

4. Åland, P. of: Resolution LTB 2/2019: Election Act for Åland., Aland Islands (2019).

5. Arbetsgruppen för Internetröstning: Informations- och kommunikationsteknik (IKT) i valprocessen. , Mariehamn (2001).

6. Arbetsgruppen för Internetröstning: Rösta per Internet? , Mariehamn (2001). 
7. Arbetsgruppen för översyn av vallagstiftningen: Slutrapport. , Mariehamn (2015).

8. Baldersheim, H. et al.: Internet Voting in Norway 2011: Democratic and Organisational Experiences. Uio.No. (2013).

9. Council of Europe: Electronic Voting Pilot in the 2008 Municipal Elections in Finland. , Strasbourg (2010).

10. Germann, M., Serdült, U.: Internet voting and turnout: Evidence from Switzerland. Elect. Stud. (2017).

https://doi.org/10.1016/j.electstud.2017.03.001.

11. Kardaş, S. et al.: Norwegian internet voting protocol revisited: ballot box and receipt generator are allowed to collude. Secur. Commun. Networks. (2016). https://doi.org/10.1002/sec.1678.

12. Krimmer, R. et al.: Challenges to Voting Processes Reengineering: Equal Treatment of Multiple Channels in Legally Binding Elections. Rev. Română Stud. Electorale. VI, 1, 61-74 (2018).

13. Krimmer, R. et al.: How much does an e-vote cost? Compared Costs per Vote in Multichannel Elections in Estonia. In: Krimmer, R. et al. (eds.) Electronic Voting. Third International Joint Conference, E-Vote-ID 2018. pp. 117-132 Springer International Publishing, Cham (2018). https://doi.org/10.1007/9783-030-00419-4.

14. Krivonosova, I.: Total cost formula for e-voting implementation. Estonia casestudy. In: Krimmer, R. and Volkamer, M. (eds.) Proceedings EVOTE2017: Second Joint International Conference on Electronic Voting E-VOTE-ID. pp. 404-406 TUT Press, Bregenz (2017).

15. Madise, Ü., Vinkel, P.: A Judicial Approach to Internet Voting in Estonia. In: Barrat Esteve, J. and Driza-Maurer, A. (eds.) E-Voting Case Law: A Comparative Analysis. pp. 105-130 Routledge (2015).

16. Mendez, F., Serdült, U.: What drives fidelity to internet voting? Evidence from the roll-out of internet voting in Switzerland. Gov. Inf. Q. 34, 3, 511-523 (2017). https://doi.org/10.1016/j.giq.2017.05.005.

17. Serrano, R.: I-Voting Costs: A Case Study of the 2019 Estonian Parliamentary Elections. Tallinn University of Technology (2019).

18. Solvak, M. et al.: E-governance diffusion: Population level e-service adoption rates and usage patterns. Telemat. Informatics. (2019). https://doi.org/10.1016/j.tele.2018.11.005.

19. Sunbdberg, J., Sjöblom, S.: Assessing Quality of Government in Autonomous Regions. In: ECPR General Conference, 4-7 September 2019, University of Wrocław. p. 17 ECPR, Wroclaw (2019).

20. Szwed, K.: Głosowanie elektroniczne na Wyspach Alandzkich - idea bez pokrycia czy realny scenariusz? PRZEGLĄD PRAWA Konst. 4, 50, 13-32 (2019).

21. Wrede, C.: E-voting in a Small Scale - the Case of Åland. In: Krimmer, R. et al. (eds.) The International Conference on Electronic Voting. E-Vote-ID 2016. pp. 109-115 TUT Press, Bregenz (2016). 